Poster Presentation Abstracts

Conclusion: Preterm born neonates with PHVD showed slightly higher ADC-values of the occipital white matter using DW-MRI at TEA. The lack of a more striking difference may be due to early treatment of PHVD at our NICU, initiated before the $\mathrm{P} 97+4 \mathrm{~mm}$ line is crossed.

203

\section{IS CEREBRAL OXYGEN SUPPLY COMPROMISED IN PRETERM INFANTS UNDERGOING CLOSURE OF PATENT DUCTUS ARTERIOSUS (PDA)?}

P. Lemmers, B. van Kooij, P. Anbeek,

F. Groenendaal, N. Poierrie, L. de Vries, F. van Bel, M. Benders

Neonatology, Wilhelmina Children's Hospital / UMC, Utrecht, The Netherlands

Background: A hemodynamically important PDA is associated with increased morbidity and should be closed pharmacological or surgical. Studies showed that surgical closure contains a risk for adverse neurodevelopmental outcome.

Objective: To monitor cerebral oxygenation by near-infrared spectroscopy ( $\mathrm{rScO} 2)$ in 3 groups of preterm infants: 9 controls without PDA (CTRL); 9 infants with pharmalogical closure (INDOI); and 9 infants with surgical closure (SURG). Monitoring started before treatment up to $48 \mathrm{~h}$ after treatment. Infants were matched for GA, BW and severity of illness. Infants had volumetric 3D-MRI at $40 w k s$ to calculate cerebral tissue volumes.

Results: $\mathrm{GA}$ and $\mathrm{BW}$ of three groups were $26.9 \pm 0.6,26.8 \pm 1.1$ and $26.4 \pm 1.0 w k s$, and $928 \pm 185$, $917 \pm 155$ and $896 \pm 141 \mathrm{~g}$ respectively. Lowest mean $\mathrm{rScO} 2$ values $\pm \mathrm{SD}$ before/during treatment were $58 \pm 6 \%$ for INDO and $53 \pm 7 \%$ for SURG vs CTRLs: $65 \pm 5 \%$ (reference values: $63-71 \%$ ), $p<0.001$. Brain volumes are shown in table1. Linear regression between ventricle volume and $\mathrm{rScO} 2$ showed a negative correlation: $r=-0.59, p<0.01$ and $r=-0.74$, $p<0.02$ for SURG only.

\begin{tabular}{|l|l|l|l|l|}
\hline & $\begin{array}{l}\text { Ventricle } \\
\text { volume }\end{array}$ & $\begin{array}{l}\text { white } \\
\text { matter }\end{array}$ & $\begin{array}{l}\text { gray } \\
\text { matter }\end{array}$ & $\begin{array}{l}\text { total } \\
\text { volume }\end{array}$ \\
\hline CTRL & $11 \pm 3$ & $158 \pm 22$ & $160 \pm 36$ & $390 \pm 33$ \\
\hline INDO & $12 \pm 2$ & $143 \pm 15$ & $161 \pm 14$ & $374 \pm 20$ \\
\hline SURG & $15 \pm 7^{*}$ & $153 \pm 18$ & $153 \pm 22$ & $383 \pm 29$ \\
\hline
\end{tabular}

[table1: * $p$
Conclusion: Lowest rScO2's were found in the SURG group, whereas ventricle volumes tended to be larger. This, and the reverse relation between rScO2 and ventricle volume in the SURG group may indicate hypoxia-induced brain tissue atrophy which (partly) explain the higher incidence of adverse outcome.

\section{4}

\section{CELLULAR IMMUNE RESPONSE AFTER HYPOXIC ISCHEMIC BRAIN INJURY IN NEONATAL MICE PERSISTS FOR MONTHS}

\author{
M. Winerdal ${ }^{1}$, M.E. Winerdal ${ }^{2}$, O. Winqvist ${ }^{2}$, \\ U. Ådén ${ }^{1}$ \\ ${ }^{1}$ Dept of Woman and Child Health, ${ }^{2}$ Dept of \\ Medicine, Karolinska Insitutet, Stockholm, Sweden
}

Background and Aims: Hypoxic ischemia $(\mathrm{HI})$ induces inflammation in the brain which can aggravate the damage. Immune cell infiltration into brain after hypoxic ischemia has previously been studied, but the timing and temporal interaction of these cells in the immature brain have not been investigated in detail before. Our aim was therefore to characterize the innate and adaptive (specific) immune response after HI.Methods: Using FACS and immunohistochemistry, innate (microglia, dendritic monocytes and neutrophils) and adaptive ( $B$ and $T$ ) cells in the brain parenchyma and spleen after brain injury were investigated. We used the Vannucci model to induce $\mathrm{HI}$ by unilateral electrocoagulation of the common carotid artery and subsequent hypoxia (10\% $\mathrm{O}_{2}$ for $60 \mathrm{~min}$ ) in 10-dayold mice. We used a number of activation, innate and adaptive cell markers at 24, 48, 72h, 1, 2 weeks and 3 months after the insult.

Results: Activation of the innate immune cells was mainly seen up to one week after $\mathrm{HI}$ in the damaged brain hemisphere and in the spleen. However, in the spleen, a long term activation of CD11b+cells was also found. The adaptive (specific) immune response was activated mainly at later timepoints (72 hrs up to 3 months after $\mathrm{HI}$ ) both in the brain and in the spleen.

Conclusions: The adaptive immune response sustained for months after brain ischemia. The functional consequences of this activation need to be studied further, but detrimental autoimmune effects or protective neuromodulation are two possible suggestions. 